\title{
Dose-response relationships and time course of the response to systemic beta adrenoreceptor agonists in infants with bronchopulmonary disease
}

\author{
RICHARD KRAEMER, PETER BIRRER, MARTIN H SCHÖNI \\ From the Department of Paediatrics, University of Berne Inselspital, Berne; and Alpine Children's Hospital \\ "Pro Juventute," Davos, Switzerland
}

ABSTRACT The lung function response to three doses of salbutamol $0.075 \mathrm{mg} / \mathrm{kg}$ given at 10 minut intervals by gastric tube was studied in 31 infants aged 2-22 months with bronchopulmonary disease (eight after the respiratory distress syndrome, 15 with wheezy bronchitis, and eight with cystio fibrosis). Lung function was measured by whole body plethysmography. Seven of 31 infants hag normal lung function and 10 of the remaining 24 had an increase in thoracic gas volume (TGV), 10 an increase in airway resistance (Raw), and four an increase in both the TGV and Raw. The response $\overrightarrow{0 \overrightarrow{0}}$ TGV and Raw to salbutamol was analysed by circular statistics, enabling analysis of couple directional data. Thirty minutes after administration of the first dose of salbutamol there was g reduction in TGV or Raw in 21 of the 24 infants, 11 showing a decrease in TGV ("volume responder' and 10 a fall in Raw ("flow responder"). These results indicate that in most infants with bronchopulmonary disease an improvement in lung function can be documented after systemg administration of beta agonists if both TGV and Raw are measured.

\section{Introduction}

There is controversy about the role of bronchodilators in infants under the age of 18 months with bronchopulmonary disease. ${ }^{1-12}$ Several studies have reported no benefit ${ }^{1-6}$ or even a paradoxical deterioration ${ }^{78}$ after beta agonists, though some infants have responded favourably ${ }^{9-12}$ and clinical observations appear to support these findings. Several technical factors could be responsible for the failure to detect a response to beta agonists in infants. In most studies the beta agonist was inhaled from a conventional jet type nebuliser and the first question is whether the drug reached its site of action. Wheezy infants commonly have upper airway obstruction and this may impede penetration of the aerosol, especially during test procedures in which the infant is asleep. A second question relates to the lung function techniques used to evaluate the response. Most studies showing no

\footnotetext{
Address for reprint requests: Dr $\mathbf{R}$ Kraemer, Department of Paediatrics, University of Berne Inselspital, CH-3010 Berne, Switzerland.
}

Accepted 14 June 1988 bronchodilator response to nebulised sympathomimetic drugs ${ }^{3-8}$ used the forced oscillation technique or inductive jacket plethysmography to measure the response. Le Souef $e t a l^{13}$ recently showed that the external compression used to generate partiail expiratory flow-volume curves (PEFV) has to standardised for both the degree of flow limitation and the lung volume. In addition, estimation of thoracje gas volume (TGV) during airway occlusion by the jacket method has been questioned. ${ }^{14}$ is Finally, Did et al recently showed that change in lung volume is $\exists$ major determinant of the bronchoconstrictor respons to methacholine challenge in healthy adults, ${ }^{16}$ the change in lung volume altering the forces of inter dependence between airways and parenchyma that oppose airway smooth muscle contraction. Change airway function has therefore to be evaluated relation to change in static lung volume, particularis as beta ${ }_{2}$ agonists have been shown to alter the pressure-volume characteristics of the lung in asthmatic children. ${ }^{17}$

There are only limited data on the dose-responfe characteristics and time course of the bronchodilator response in infants. In a previous study of bee agonists in asthmatic children we suggested thgt 
patients should be stratified into groups according to whether they have predominant pulmonary hyperinflation, bronchial obstruction, or a combination of the two. ${ }^{18}$ The purpose of the present study was to evaluate the dose-response relationships and time course of systemically administered salbutamol in infants with lung disease, allocated according to their initial lung function to one of these functional groups.

\section{Methods}

\section{PATIENTS}

Thirty one infants aged 2-22 months with bronchopulmonary disease were investigated. They fell into three diagnostic groups. Eight patients who had had respiratory distress syndrome due to hyaline membrane disease or neonatal pneumonia were investigated two or three months after the acute illness. All were premature infants (mean gestational age 34.2 (range 29-37) weeks) and their mean birth weight was 1.8 (range 1.1-2.9) kg. All had been intubated and ventilated mechanically or by continuous positive airway pressure with an increased inspired oxygen concentration for several days (mean 9.2 (range 2.5-22 days). Fifteen infants had been diagnosed as having wheezy bronchitis and eight as having cystic fibrosis affecting the lungs. None of the patients had been treated with beta agonists previously. Informed consent was obtained from the parents and the study was approved by the local ethical committee.

\section{LUNG FUNCTION MEASUREMENTS}

Thoracic gas volume and airway resistance (Raw) were measured by an adaptation of the plethysmographic technique ${ }^{19}$ with an infant plethysmograph (Jaeger, Wuerzburg, West Germany). All measurements were done 15-20 minutes after a feed and after the infants had been sedated with chloral hydrate $(80$ $\mathrm{mg} / \mathrm{kg}$ ). During the plethysmographic measurements pulse oximeter monitoring of heart rate and arterial oxygen saturation (Biox III,Omeda, Bolder, USA) was performed. The infant was placed in the supine position inside a whole body infant plethysmograph. A mask, sealed around the nose and mouth to ensure an airtight fit, was carefully manipulated into place for the measurements. After the box had been closed the infant breathed air from the box through a triple valve system until thermal equilibrium had been reached between the infant and the box. A differential pressure transducer was used to detect changes in box pressure relative to a compensating chamber of similar volume $(\mathrm{Pb})$. The infant was then switched to the BTPS bag, from which air at $36.5^{\circ} \mathrm{C}$ and $100 \%$ humidity was rebreathed. The phase relationship between flow (V), measured by a baby size pneumotachograph, and box pressure $(\mathrm{Pb})$ was checked by displaying both signals on an oscilloscope until a stable, almost closed pressure-flow loop was obtained. From the tracing of $\dot{V}$ and $\mathrm{Pb}$ the uncorrected specific airway resistance (sRaw) and its reciprocal, specific airway conductance (sGaw), were calculated. Changes in mouth pressure ( $\triangle \mathrm{PM})$ were obtained after the shutter was closed to occlude the airway while the infant made two or three respiratory efforts, breathing in most cases at 30-40 breaths a minute. This varied little between infants or in the same infant between studies. TGV was measured from the angle of $\beta$ of the box pressure $\Delta \mathrm{Pb} /$ $\triangle \mathrm{PM}$ plot (fig 1) and corrected for instrument dead space $(30 \mathrm{ml})$. Occlusions were performed at resting lung volume (TGVEE) and at end inspiration (TGVEI), and the mean of these two values (TGVEI minus tidal volume) was taken as TGV. Raw was calculated from the angles $\alpha_{1}, \alpha_{2}$, and $\alpha_{3}$ of the $\Delta \mathrm{Pb} / \Delta \dot{\mathrm{V}}$ plot (fig 1 ). Inspiratory airway resistance (Raw) was obtained from angle $\alpha_{1}$, expiratory airway resistance between peak flow points $\left(\mathrm{Raw}_{\mathrm{Ep}}\right)$ from angle $\alpha_{2}$, and expiratory airway resistance between peak pressure points $\left(\operatorname{Raw}_{\mathrm{E}, \mathrm{pp}}\right)$ from angle $\alpha_{3}$. The resistance of the pneumotachograph $(0 \cdot 18 \mathrm{kPa})$ was substracted from each calculated value of Raw. Only $R_{a w}$ epf was used for statistical evaluation. To compare infants at different growth stages lung function data were expressed as percentages of predicted values according to the values given by Stocks and Godfrey. ${ }^{20}$

The infants were stratified into three functional groups according to the results of lung function tests: predominant hyperinflation (TGV $>130 \%$ pred,

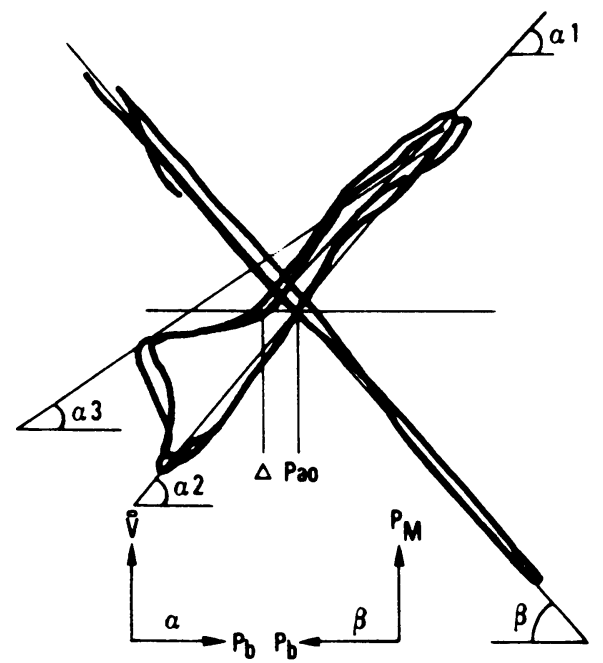

Fig 1 Recording of the plethysmographic curves: (1) flow $(\mathrm{V})$ versus box pressure $(\mathrm{Pb})$ plot to calculate resistances according to the angles $\alpha_{1}, \alpha_{2}, \alpha_{3}$ (see text) and (2) pressure at the mouth (PM) versus box pressure to calculate thoracic gas volume (TGV) according to the angle $\beta$. 
Table 1 Characteristics of the three groups of infants

\begin{tabular}{|c|c|c|c|}
\hline & $R D S$ & Wheeze & $C F$ \\
\hline $\begin{array}{l}\text { Number } \\
\text { Sex (M:F) } \\
\text { Gestational age (weeks, mean (SD)) } \\
\text { Postconceptional age (weeks, mean } \\
\text { (SD)) } \\
\text { Body weight (kg, mean (SD)) }\end{array}$ & $\begin{array}{c}8 \\
7: 1 \\
34 \cdot 2 \\
(4 \cdot 2) \\
58 \cdot 1 \\
(18 \cdot 1) \\
5 \cdot 9 \\
(2 \cdot 9)\end{array}$ & $\begin{array}{c}15 \\
9: 6 \\
39.4 \\
(1.2) \\
69.8 \\
(24.5) \\
7.6 \\
(2.2)\end{array}$ & $\begin{array}{c}8 \\
3: 5 \\
39.5 \\
(1.4) \\
66.6 \\
(23.5) \\
5.9 \\
(2.6)\end{array}$ \\
\hline
\end{tabular}

RDS-respiratory distress syndrome; $\mathbf{C F}-$ cystic fibrosis.

Raw $\leqslant 130 \%$ pred); hyperinflation and bronchial obstruction (TGV $>130 \%$ pred, Raw $>130 \%$ pred) and bronchial obstruction without hyperinfiation (TGV $\leqslant 130 \%$ pred, Raw $>130 \%$ pred). On the basis of the data of Stocks and Godfrey, values 2 standard deviations above or below the mean TGV or Raw are equivalent to differences of $14 \%$ and $10 \%$ of the predicted values.

\section{BRONCHODILATOR ADMINISTRATION}

After a reproducible set of at least two baseline measurements had been obtained a cumulative salbutamol dose-response study was carried out. Salbutamol $0.075 \mathrm{mg} / \mathrm{kg}$ was administered orally by a nasogastric tube on three occasions at 10 minute intervals. Lung function measurements were repeated five and 10 minutes after each dose to give six postsalbutamol measurements. All patients completed the test procedure within 30 minutes without waking.

\section{ANALYSIS}

The TGV and Raw responses to salbutamol were analysed by circular statistics. ${ }^{22} 2$ This allows evaluation of directional data or coupled variables, which cannot be analysed by techniques appropriate for the usual Euclidean type variables. ${ }^{2324}$ The procedure of the two dimensional vector analysis evaluating changes in TGV and Raw after administration of salbutamol in relation to dose and time is described under "Results." Differences between groups were evaluated by the non-parametric Wilcoxon-MannWhitney U test.

Table 2 Mean (SD) thoracic gas volume (TGV), airway resistance (Raw), and specific airway conductance (sGaw) in the infants with abnormal lung function

\begin{tabular}{lccc}
\hline & $R D S$ & Wheeze & $C F$ \\
\hline $\begin{array}{l}\text { No with abnormal lung } \\
\text { function/total }\end{array}$ & $5 / 8$ & $1 / 15$ & $1 / 8$ \\
TGV & 160 & 182 & 140 \\
(\% pred) & $(92)$ & $(103)$ & $(54)$ \\
$\begin{array}{l}\text { Raw } \\
\text { (\% pred) }\end{array}$ & 142 & 137 & 154 \\
sGaw & $(88)$ & $(57)$ & $(95)$ \\
(\% pred) & 58 & 52 & 66 \\
& $(16)$ & $(30)$ & $(26)$ \\
\hline
\end{tabular}

Abbreviations as in table 1.

\section{Resultus}

Details of the subjects, within the three diagnos groups, are summarised in table 1. Gestational age, postconceptional age, and weight were lower in the respiratory distress syndrome group than in whee⿳亠丷厂巾 infants or (with the exception of weight) those with cystic fibrosis $(p<0.01)$.

No serious side effects followed the administratiog of the beta agonist. Pulse oximetry showed a meas increase of $18 \%$ in heart rate 30 minutes after the first salbutamol administration. Oxygen saturation fêf below $88 \%$ in two infants from the respiratory distress syndrome group and in three of the wheezy infants but this was quickly improved by increasing the oxygen content of the inspired air.

TGV, Raw, and sGaw were normal in seven of the 31 patients (table 2). TGV was increased in infan@ who had had respiratory distress syndrome $(159 \%$ $(92 \%)$ pred) and wheezy bronchitis (181\% (102\% pred); Raw was increased in infants with cystic fibrosis

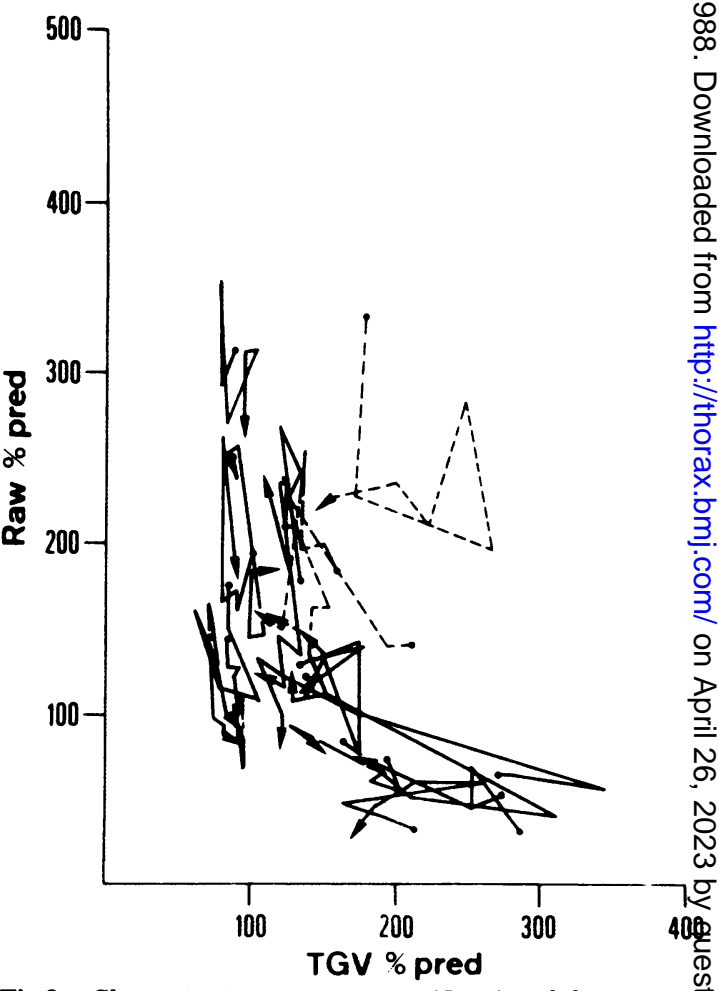

Fig 2 Change in airways resistance (Raw) and thoracic gas volume (TGV) in individual infants in response to salbutamo ( $0.075 \mathrm{mg} / \mathrm{kg}$ bodyweight) given on three occasions intragastrically (origin of the arrows (.) before medication, $\stackrel{D}{\rho}$ tip of the arrows $(->)$ after medication). Each segment of $\vec{\curvearrowright}$ the line represents change over a five minute interval. Right lower quadrant: infants with increased TGV; left upper quadrant: infants with increased Raw. Dotted lines: patients 8 of mixed type group. 


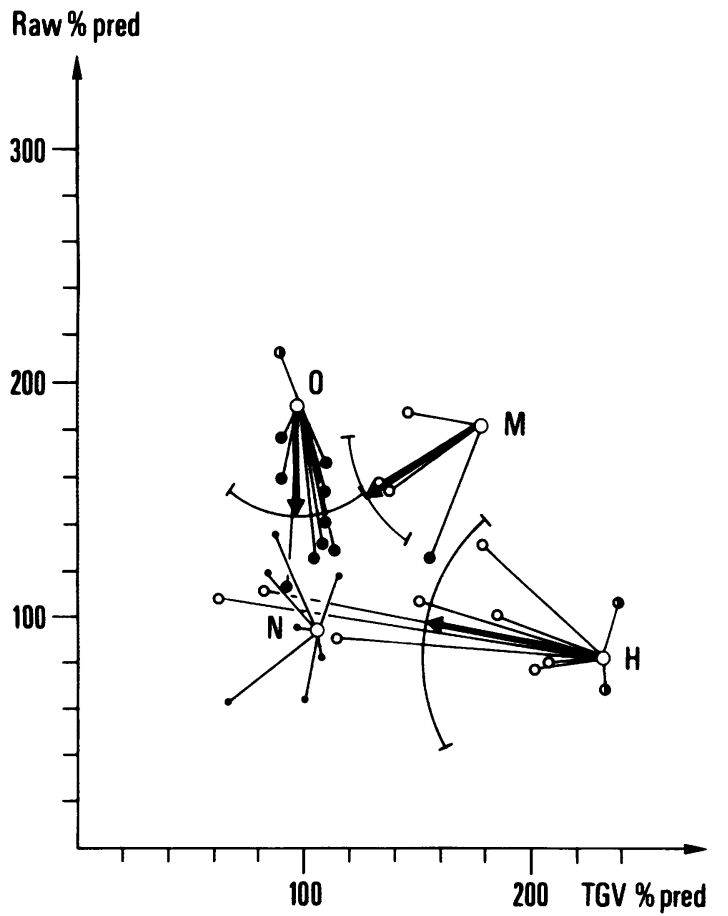

Fig 3 Unit circles $(r=1)$ as analogue of the histogram for the circular statistics; mean angles (dark) with 1 SD in the four functional groups. $N$-with initially normal lung function; $H$-infants with increased thoracic gas volume (TGV); $M$-mixed type, increased TGV and airway resistance ( $R a w) ; O$-infants with increased Raw.

(153\% (95\%) pred). The range of values was wide, however, and the differences between groups were not statistically significant. The scatter of TGV, Raw, and sGaw values within the three diagnostic groups was similar, so the data from the three groups were evaluated together. The younger the infant was, independent of the diagnostic group, the higher the TGV.

Figure 2 shows individual changes in TGV ( $x$ axis) and Raw ( $y$ axis) after salbutamol. The patients in whom both TGV and Raw were increased (broken lines) can be distinguished from those with an increase in TGV alone (right lower quadrant) and from those with an increase in Raw alone (left upper quadrant). Each segment represents the vectoral changes in TGV and Raw over five minutes.

The angles of the changes were plotted on a unit circle (radius $=1$ ) by means of circular statistics ${ }^{21-24}$ to obtain a graphical analogue of a histogram (fig 3), the origin of each vector (values before drug administration) and the magnitude of change after salbutamol being disregarded. The components and polar
Table 3 Polar coordinates $(r, \varphi)$ of the mean vectors and dispersion of significance $z$ obtained by circular statistics in the infants according to initial lung function

\begin{tabular}{lcccc}
\hline Group & $n$ & $r$ & $\varphi$ & $z$ \\
\hline Hyperinflation & 10 & 2.9 & $\begin{array}{c}169.8 \\
(40.6)\end{array}$ & $5.6^{* *}$ \\
$\begin{array}{l}\text { (SD) } \\
\text { (SD) }\end{array}$ & 4 & 3.6 & $\begin{array}{c}148.7 \\
(26.6)\end{array}$ & $3.2^{*}$ \\
$\begin{array}{c}\text { Obstruction } \\
\text { (SD) }\end{array}$ & 10 & 7.7 & $\begin{array}{c}270.8 \\
(38.9)\end{array}$ & $5.9 * *$ \\
\hline
\end{tabular}

${ }^{*} \mathrm{p}<0.05, * \mathrm{p}<0.01$.

coordinates ( $r$ and $\varphi$ ) of the empirical mean vector of each groups were calculated after 10, 20, and 30 minutes on the assumption of a unimodal circular distribution. The response to the beta ${ }_{2}$ agonist was defined by the direction and magnitude of the mean vector.

The mean vectors of the groups with a raised TGV (hyperinflated), with increased Raw (bronchial obstructed), and with both (mixed type) point towards the group with initially normal values. The test of significance $(z)$ of the mean vectors 30 minutes after salbutamol in each group is represented by its polar coordinates $(r, \varphi)$ and the results are summarised in table 3. The Rayleigh test, ${ }^{23}$ as modified by Greenwood and Durand ${ }^{24}$ was used to test "randomness." The significance of the unimodal distribution of the mean vector compared with the critical values $z_{p}$ for $p=5 \%$ and $1 \%$ was calculated. There was a directional change towards functional improvement in each group (table 3, fig 3; p $<0.01$ in infants with increased TGV or Raw alone and $<0.05$ in patients with both abnormalities).

The final polar coordinates (vector $r$ and angle $\varphi$ ) represent individual responses to salbutamol at $\mathbf{3 0}$ minutes. The infants were assigned to different response categories: those with vector angles of $0-134^{\circ}$ degrees and $315-360^{\circ}$ were categorised as "non-responders" (fig 4); those with vector angles of 135-224 (in whom the end expiratory resting level had fallen) as "volume responders"; and those with vector angles of 225-314 (a decrease in Raw) as "flow responders."

Table 4 Time course of beta ${ }_{2}$ response within the functional groups

\begin{tabular}{|c|c|c|c|c|}
\hline \multirow[b]{2}{*}{ Group } & \multirow{2}{*}{$\begin{array}{l}\text { Type of } \\
\text { response }\end{array}$} & \multicolumn{3}{|c|}{ Time (min) } \\
\hline & & 10 & 20 & 30 \\
\hline $\begin{array}{l}\text { Hyperinflation } \\
\quad(\mathrm{n}=10)\end{array}$ & $\begin{array}{l}\text { Volume } \\
\text { Flow } \\
\text { None }\end{array}$ & $\begin{array}{l}5 \\
0 \\
5\end{array}$ & $\begin{array}{l}6 \\
0 \\
4\end{array}$ & $\begin{array}{l}8 \\
0 \\
2\end{array}$ \\
\hline $\begin{array}{l}\text { Mixed type } \\
\quad(n=4)\end{array}$ & $\begin{array}{l}\text { Volume } \\
\text { Flow } \\
\text { None }\end{array}$ & $\begin{array}{l}0 \\
0 \\
4\end{array}$ & $\begin{array}{l}3 \\
1 \\
0\end{array}$ & $\begin{array}{l}3 \\
1 \\
0\end{array}$ \\
\hline $\begin{array}{l}\text { Obstruction } \\
\quad(n=10)\end{array}$ & $\begin{array}{l}\text { Volume } \\
\text { Flow } \\
\text { None }\end{array}$ & $\begin{array}{l}1 \\
5 \\
4\end{array}$ & $\begin{array}{l}0 \\
7 \\
3\end{array}$ & $\begin{array}{l}0 \\
9 \\
1\end{array}$ \\
\hline
\end{tabular}




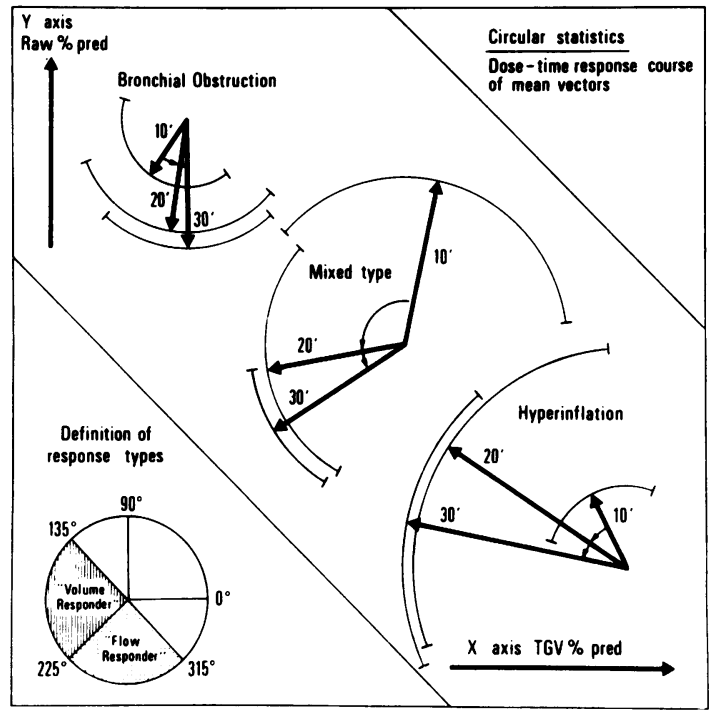

Fig 4 Dose-response course after cumulative dose of salbutamol represented by the mean vectors and angle distribution for each 10 minute interval within the three functional groups with initially abnormal lung functions. TGV-thoracic gas volume; Raw-airway resistance.

The repartitioning of patients into non-responders, volume responders, and flow responders within the three functional groups in relation to time and cumulative dose of salbutamol is summarised in table 4. Thirty minutes after salbutamol only three infants were categorised as "non-responders." Eight of the 10 infants with increased TGV were "volume responders" and two non-responders. Nine of the 10 with increased Raw were "flow responders" and one was a non-responder. In the four infants with an increase in TGV and Raw three were "volume responders" and one a "flow responder."

Figure 4 presents the dose-time response course after salbutamol represented by the mean vectors and angle distribution within the three functional groups. The mean vectors have turned counter clockwise to achieve a preferred direction towards the centre of values predicted for both TGV and Raw. Hyperinflated infants showed a predominant "volume response," whereas infants with bronchial obstruction showed a predominant "flow response."

\section{Discussion}

The resistance of an airway bears an inverse fourth power relationship to its diameter. ${ }^{25}$ A progressively greater change in resistance is therefore expected for a given change in smooth muscle length (and hence inspiratory lung volume) as an airway narrows. This implies that the bronchodilator response to bet agonists must be measured in infants by methods tha evaluate changes in airway function in relation t $\bar{Q}$. changes in static lung volume, as we have alreadf shown in older asthmatic children. ${ }^{18}$

The infant whole body plethysmograph allows $\%$ static lung volume and airway resistance to be measured. Specific patterns for each disease group were expected. The pattern of the initial lung functio $\vec{B}$ disorder was, however, linked more with the severits? of the disease and the age of the infant than with the clinical picture (respiratory distress syndrome, wheez bronchitis, cystic fibrosis). A response to the systemic beta agonist was seen in 21 of 24 infants with bronchopulmonary disease. Of the responders, 11 of the 21 infants showed a decrease in end expirator resting level (volume responders) and 10 a decrease in Raw (flow responders).

Technical aspects The measurement of TGV bo plethysmography depends critically on the accuracy with which mouth pressure reflects mean alveolar pressure during respiratory efforts against a close shutter, and on the precision with which plethyso mograph chamber pressure reflects change in alveolatg volume under these dynamic conditions. Severat studies in adults with airway obstruction have founs that TGV may be overestimated because changes if mouth pressure underestimate changes in meas alveolar pressure during respiratory efforts against an occlusion. ${ }^{26}$ Plethysmographic measurements ig infants have recently been questioned..$^{28-30}$ In our study TGV in one infant who had had bronchitis was as higt as $445 \%$ pred; severe hyperinflation was noted on the chest radiograph. In contrast, Godfrey et a ${ }^{p 0}$ found that more than half of the infants studied with recurrent wheeze after bronchiolitis had low values foip TGV. In their study the administration of salbutam to 21 infants resulted in a small rise in TGV (from $78 \%$ to $83 \%$ pred), whereas in our study TGV decreased i the 15 wheezy infants from $174 \%$ to $131 \%$ predicted These discrepancies are presumably due to differences in the techniques used to measure lung volume. II contrast to our technique and that used by Stocks ${ }^{20} \mathrm{im}$ the study from which the normal values were taken, measurement of forced flow-volume curves was carried out in the study by Godfrey with the infants id a double walled squeeze jacket covering the child thorax and abdomen in the infant plethysmograpto Although the authors state that the jacket did not restrict measurement of TGV, the question must remain of whether respiration was really free frond compressive influences and whether $\mathrm{Pb}$ changes weer not altered as a result of the jacket-and therefor: whether, especially in wheezy infants, $\mathrm{Pb}$ chang would reflect change in alveolar pressure accurately. is also possible that lung volumes remained low afte्तु 
the repeated rapid inflations of the jacket used to produce forced expiration. In younger infants with more compliant chest walls such manoeuvres might reduce lung volume and cause hyperinflation to be underestimated.

Circular statistics Two standard deviations above or below the mean predicted values are equivalent to a difference of $14 \%$ of the predicted values for TGV and $10 \%$ for Raw. In this analysis the same absolute weighting was given to changes for both variables in the graphical representation of the data. Calculations based on the standard deviation of the normal values ${ }^{17}$ would probably have been a more appropriate basis for describing the directional data.

Pulmonary hyperinflation We have shown previously that younger infants have more pronounced pulmonary hyperinflation more often than older infants. ${ }^{31}$ The absolute dimensions of the airways from the trachea to the respiratory bronchioles are smaller ${ }^{32}$ and the less rigid chest wall of young infants provides little passive support to the lungs, so that end expiratory resting volume increases more readily. ${ }^{32}$ The mechanisms that lead to hyperinflation may be similar to those described in adults. ${ }^{33}$ The effect of bronchial obstruction is greater in expiration, so the inspiratory tidal volume may not be expelled in the time available for expiration. The end expiratory resting level (functional residual capacity) will rise accordingly until a new point of equilibrium is reached. The increase in the elastic recoil of the lungs and chest wall will then aid expiration and the increased elastic traction on the airways will increase their intrinsic calibre. Our results, consistent with findings in adults, show that lung elastic recoil decreases after treatment with beta agonists in asthmatic children, especially those with large lung volume. ${ }^{17}$ This may be due to dilatation of terminal lung units relaxing smooth muscle in the alveolar ducts.

Efficacy of beta agonists Prendiville and colleagues initially reported paradoxical bronchoconstrictor responses to nebulised salbutamol in wheezy infants. ${ }^{8}$ Bronchoconstriction in response to histamine was, however, found in infants by the same group, ${ }^{34}$ and more recently ${ }^{35}$ salbutamol was shown to protect against the bronchoconstrictor response to histamine. In all three studies PEFV was measured. The conclusion from these somewhat contradictory findings was that salbutamol has no effect when there is chronic airway narrowing, but has a protective effect when the infant is exposed to an irritant trigger. We believe, however, that technical problems may explain these conflicting results. It was assumed in these studies that maximum flow at functional residual capacity before and after salbutamol was measured at the same end expiratory resting level, an assumption that is unproved as FRC and TGV were not measured. The absence of a bronchodilator response may be due to the fact that they studied severely ill patients, in whom other factors may have been contributing. Using the same technique, Tepper $^{36}$ found a response to beta agonists in 10 healthy male infants after methacholine challenge. FRC was not measured, but it was assumed to have been within the normal range as the subjects were healthy.

In 50 infants with wheezy bronchitis ${ }^{10} 15$ showed an increase in specific conductance (calculated by dividing oscillatory conductance by TGV). Responders could not be differentiated from non-responders by family history or laboratory evidence of atopy. The results, contradicting those of some previous studies, ${ }^{13}$ were thought to be explained by change in lung volume that had masked an effect of treatment on conductance. $^{10}$

These observations in general support our findings that infants with persistent signs of bronchopulmonary disease respond to bronchodilators, if both changes in TGV and airway function are taken into account. The improvement in TGV may be due to improvement of flow by bronchodilatation, with a consequent decrease in end expiratory resting level. Decrease in lung volume will itself narrow the airways and airway resistance may not fall unless the diameter of the airway has changed substantially.

\section{References}

1 Phelan PD, Williams HE. Sympathomimetic drugs in acute viral bronchiolitis. Pediatrics 1969;44:493-7.

2 Radford M. Effect of salbutamol in infants with wheezy bronchitis. Arch Dis Child 1977;50:535-8.

3 Rutter N, Milner AD, Hiller EJ. Effect of bronchodilators on respiratory resistance in infants and young children with bronchiolitis and wheezy bronchitis. Arch Dis Child 1975;50:719-22.

4 Lenny W, Milner AD. At what age do bronchodilators work? Arch Dis Child 1978;53:532-5.

5 Lenney W, Milner AD. Alpha and beta adrenergic stimulants in bronchiolitis and wheezy bronchitis in children under 18 months of age. Arch Dis Child 1978; 53:707-9.

6 Stockes GM, Milner AD, Hodges IGC, Henry RL, Elphick MC. Nebulised therapy in acute severe bronchiolitis in infancy. Arch Dis Child 1983;58:279-83.

7 O'Callaghan O, Milner AD, Swarbrick A. Paradoxical deterioration in lung function after nebulised salbutamol in wheezy infants. Lancet 1986;ii:1424-5.

8 Prendiville A, Green S, Silverman M. Paradoxical response to nebulised salbutamol in wheezy infants, assessed by partial expiratory flow-volume curves. Thorax 1987;42:86-91.

9 Logvinoff MM, Lemen RJ, Taussig LM, Lamont BA. Bronchodilators and diuretics in children with bronchopulmonary dysplasia. Pediatr Pulmonol 1985;1: 198-203. 
10 Soto ME, Sly PD, Uren E, Taussig LM, Landau LI. Bronchodilator response during acute viral bronchiolitis in infancy. Pediatr Pulmonol 1985;2:85-90.

11 Sosulski R, Abbasi S, Bhutani VK, Fox WW. Physiologic effects of terbutaline on pulmonary function of infants with bronchopulmonary dysplasia. Pediatr Pulmonol 1986;2:269-73.

12 Gomez-Del Rio M, Gerhardt T, Hehre D, Feller R, Bancalari E. Effect of a beta-agonist nebulization on lung function in neonates with increased pulmonary resistance. Pediatr Pulmonol 1986;2:287-91.

13 Le Souef PN, Hughes DM, Landau LI. Effect of compression pressure on forced expiratory flow in infants. $J$ Appl Physiol 1986;61:1639-46.

14 Helms P, Taylor BW, Milner AD, Hatch DJ. Critical assessment of jacket plethysmographs for use in young children. J Appl Physiol 1982;52:267-73.

15 Silverman M. Bronchodilator for wheezy infants? Arch Dis Child 1984;59:84-7.

16 Ding DJ, Martin JG, Macklem PT. Effects of lung volume on maximal metacholine-induced bronchoconstriction in normal humans. J Appl Physiol 1987;62: 1324-30.

17 Kraemer R, Geubelle F. Lung distensibility and airway function in asthmatic children. Pediatr Res 1984;18: 1154-9.

18 Kraemer R, Meister B, Schaad UB, Rossi E. Reversibility of lung function abnormalities in children with perennial asthma. J Pediatr 1983;102:347-50.

19 DuBois AB, Bothello SY, Bedell GN, Marshall R, Comroe JH. A rapid plethysmographic method for measuring TGV: comparison with $\mathrm{N} 2$ washout for measuring FRC in normal subjects. $J$ Clin Invest 1965; 35:322-6.

20 Stocks J, Godfrey S. Specific airway conductance in relation to postconceptional age during infancy. $J$ Appl Physiol 1977;43:141-54.

21 Batschelet E. Statistical methods for the analysis of problems in animal orientation and certain biological rhythmus. American Institute of Biological Sciences, 1965:23-40.

22 Mardia KV. Statistics of directional data. New York: Academic Press, 1972.

23 Rayleigh Lord (Strutt JS). The problem of random walk. Nature 1905;72:318-25.
24 Greenwood JA, Durand D. The distribution and com ponents of the sum of $\mathrm{n}$ random unit vectors. Ann Math Statist 1955;26:233-46.

25 Briscoe WA, DuBois AB. The relationship betwe airway resistance, airway conductance and lun volume in subjects of different ages and body size. J Clin Invest 1958;37:1279-85.

26 Shore S, Milic-Emili J, Martin JG. Reassessment of body plethysmographic technique for the measurement of thoracic gas volume in asthmatics. Am Rev Respir Did 1982;126:515-20.

27 Brown R, Ingram RH, McFadden ER. Problems in the plethysmographic assessment of changes in total lung capacity in asthma. Am Rev Respir Dis 1978;118. 685-92.

28 Beardsmore CS, Stocks J, Silverman M. Problems in the measurement of thoracic gas volume in infancy. $J$ AppD Physiol 1958;52:995-9.

29 Helms P. Problems with plethysmographic estimation of lung volume in infants and young children. $J$ Appt Physiol 1982;53:698-702.

30 Godfrey S, Beardsmore CS, Maayan C, Bar-Yishay Can thoracic gas volume be measured in infants wit airway obstruction. Am Rev Respir Dis 1986;133 245-51.

31 Kraemer R, Birrer P, Sennhauser FH, Schöni MH. Shorttime response characteristics of salbutamol in infants with bronchopulmonary disease. Eur J Clin Pharmac 1988;34:339-42.

32 Polgar G, Weng TR. The functional development of the respiratory system. Am Rev Respir Dis 1979;129 625-95.

33 Woolcock AJ, Read J. Improvement in bronchial asthm旅 not reflected in forced expiratory volume. Lancet 1965 ii:1323-5.

34 Prendiville A, Green S, Silverman M. Bronchial responsiveness to histamine in wheezy infants. Thorax 198 42:92-9.

35 Prendiville A, Green S, Silverman M.Airway responsive ness in wheezy infants: evidence for functional betio adrenergic receptors. Thorax 1987;42:100-4.

36 Tepper RS. Airway reactivity in infants: a positivi response to metacholine and metaproterenol. $J$ App Physiol 1987;62:1155-9. 